gether while the male Mallard was two or three feet away. Once the male Pintail stopped swimming and turned toward the male Mallard which immediately turned and swam away. The group was flushed from the same slough on May 14 and 16, but they were not seen after this date.

A check of the nesting cover toward which the female Mallard was originally seen walking, disclosed no nest, but three Mallards' nests which had been crushed and eaten by predators were found within 100 yards of this point. One of them might have belonged to the hen in question.

During the observations it was noted that the male Pintail, through threat postures and aggressive rushes, continually kept the male Mallard away from the hen. Yet the hen showed no such threatening attitudes toward the Pintail, nor did she show any escape reactions when the Pintail swam or walked close to her. Apparently this drake, of a different species, possessed none of the signal characteristics necessary to elicit attack or escape in the hen. One can merely speculate as to why the male Mallard did not attack the male Pintail (or if he were merely associating with a mixed pair) and why the hen attracted the male Pintail.

Sibley (op. cit.) has pointed out that peak times of pairing vary among species and that this functions as an isolating mechanism. Furthermore, he noted that the various intricate signal movements of males in a courting party possibly prevent species from forming mixed pairs. From the above incident it is evident that, even though mixed pairs are not commonly formed, males of some species may, at times, accompany pairs of other species. It is suggested that if the attached male is dominant over the male of the pair, he could play a part in the fertilization of any eggs which the hen lays. Even if the foreign male is not dominant, he may passivly accompany the pair and play a part in fertilizing the eggs.

\title{
Green-winged Teal-Mallard Pair Association
}

By R. W. Nero, Saskatchewan Museum of Natural History.

Close association of various species of birds is occasionally observed, especially in waterfowl and shorebirds which often move about in compact units. The general phenomenon of more heterogeneous species flying together momentarily when suddenly flushed has received several comments (H. Brackbill, 1952. Birds becoming "caught" in flocks of other species. Wilson Bulletin, 64:44). However, an observation made by Elmer Fox and myself of a close association between a hen Mallard (Anas platyrhynchos) and a drake Green-winged Teal (Anas carolinensis) seems unusual and worth recording. On May 11, 1957, near some shallow sloughs south of Regina at 4.00 p.m. we saw a drake Mallard and hen and a male Green-winged Teal, fly up together and circle wildly about several times with the Teal keeping very. close to the hen. They landed as a group and again the Teal stayed close beside the hen Mallard. The drake Mallard appeared to be unconcerned. We watched them for a while, then, wondering if they would repeat the pattern, flushed them from the slough. They again flew up as a group and landed on another slough several hundred yards away. During the flight and after they landed the Teal was close beside the hen. Upon landing the drake Mallard moved away to confront another drake Mallard. A few minutes later the original trio flew back to the location where we had first seen them. When we finally drove away the three were still close together. The association between the Teal and the hen seemed based on a very close bond, suggestive of pairing. A large number of hybrid ducks, including a cross between a Mallard and a Green-winged Teal, have been reported (E. L. Cockrum, 1952. A check-list and bibliography of hybrid birds in North America north of Mexico. Wilson Bulletin, 64:140-159). Presumably, a relationship similar to that described here must have prevailed in many cases. The drake Mallard of the trio, evidently paired or at least attached to the hen Mallard, appeared to have developed a tolerance toward the Teal. The exact nature of this peculiar relationship remains unanswered, but other observations of a similar nature may be helpful in this respect. 